\title{
Identification and Characterization of Phomopsis amygdali and Botryosphaeria dothidea Associated with Peach Shoot Blight in Yangshan, China
}

Yanli Tian, College of Plant Protection and Key Laboratory of Integrated Management of Crop Diseases and Pests, Ministry of Education, Nanjing Agricultural University, Nanjing 210095, China; Yuqiang Zhao, Institute of Botany, Jiangsu Province and Chinese Academy of Sciences (Nanjing Botanical Garden Mem. Sun Yat-Sen), Jiangsu Key Laboratory for the Research and Utilization of Plant Resources, Nanjing 210014, China; Ting Sun, Lv Wang, and Jun Liu, College of Plant Protection and Key Laboratory of Integrated Management of Crop Diseases and Pests, Ministry of Education, Nanjing Agricultural University; Xiaofeng Ma, Huishan Agricultural Technology Extension Service Station, Wuxi, 214174, China; and Baishi Hu, ${ }^{\dagger}$ College of Plant Protection and Key Laboratory of Integrated Management of Crop Diseases and Pests, Ministry of Education, Nanjing Agricultural University

\begin{abstract}
Peach (Prunus persica (L.) Batsch) is produced locally in Yangshan, Wuxi City, China. In recent years, a widespread shoot blight has been observed in many peach orchards of Yangshan that kills the twigs and results in high losses in fruit production. Disease incidences ranged from 10 to $20 \%$ in the affected orchards and, in extreme cases, $40 \%$ of the trees were affected. Shoot blight of peach is caused by a fungus, previously identified as Phomopsis amygdali. Between 2014 and 2015, samples were collected four times from three peach orchards located in Yangshan to understand the etiology of shoot blight. Interestingly, two types of shoot blight symptoms were observed: one characterized by necrotic lesions with rings and one without rings. Based on conidial morphology, cultural characteristics, and analysis of nucleotide sequences of three genomic regions (the internal transcribed spacer region, a partial sequence of the $\beta$-tubulin gene, and the translation elongation factor 1- $\alpha$ ), isolates were identified as $P$. amygdali and Botryosphaeria dothidea.

Remarkably, most of the $P$. amygdali isolates were recovered from twigs showing necrotic lesions without rings. In contrast, most of the $B$. dothidea isolates were recovered from twigs with rings in the necrotic lesions. Correlations among pathogens, sampling regions, and disease symptoms were noted, and growth rates of these pathogens were characterized. Pathogenicity tests showed that $B$. dothidea isolates could induce necrotic lesions with rings but $P$. amygdali isolates could only induce necrotic lesions. Moreover, the $B$. dothidea isolates exhibited higher levels of virulence than $P$. amygdali isolates on the peach twig. Additionally, high frequencies of detection of both $P$. amygdali and $B$. dothidea from buds indicated that buds may be the primary site of fungal invasion. Cankers and necrotic twigs may also serve as infection courts. Our results suggest that $B$. dothidea and $P$. amygdali are the common causal agents of peach shoot blight in Yangshan, China. This finding provides a basis for the development of effective management strategies.
\end{abstract}

Peach (Prunus persica (L.) Batsch) originated and has a long history of cultivation in China. Yangshan is one of four famous peachproducing areas of China and the Honey Peach has been cultivated there for 70 years (Dai 1998). In 2015, the Yangshan Honey Peach industry was cultivated on 2,000 ha and yielded 15,000 tons of fruit. Honey Peach is the main cash crop for local growers (Chen and Tian 2016). In recent years, a shoot blight disease that resulted in brown cankers around buds on shoots or twigs of peach trees has been widely observed in many orchards in Yangshan. Disease incidence ranged from 10 to $20 \%$ in the affected orchards and, in extreme cases, $40 \%$ of the trees were affected. This disease killed shoots and branches and resulted in high yield losses. Shoot blight has become a serious limiting factor in the growth of peach trees in Yangshan.

Several fungal diseases have been observed in peach stem and branch cankers. The common diseases include Valsa canker (as known as Cytospora canker or Leucostoma canker), caused by the fungi Leucostoma persoonii and L. cincta (Fr.) Höhn. (Puterka et al. 1993); and Phomopsis cankers (twig blights) caused by the fungus Phomopsis amygdali (Smit et al. 1996). A recent study reported that three species (Botryosphaeria dothidea, Diplodia seriata, and Lasiodiplodia theobromae) caused gummosis of peach trees in Hubei Province, China (Wang et al. 2011).

${ }^{\dagger}$ Corresponding author: Baishi Hu; E-mail: hbs@njau.edu.cn

Y. Tian and Y. Zhao contributed equally to this research.

Funding: This study was supported financially by Crop Pest Monitoring and Control (2130108).

Accepted for publication 10 June 2018.

C 2018 The American Phytopathological Society
The pathogen that caused shoot blight on Yangshan Honey Peach trees was referred to by Ji et al. (2013) only as P. amygdali. Interestingly, while studying the etiology of peach shoot blight in Yangshan, we found two types of shoot blight symptoms, including necrotic lesions with and without rings. However, the etiology of the two types of shoot blight symptoms were not understood until now. The objective of this study was to elucidate the etiology of shoot blight of peach in Yangshan.

\section{Materials and Methods}

Field survey, disease symptoms, and fungal isolation. From 2014 to 2015, a field survey was carried out to determine the incidence of peach shoot blight in three orchards in Yangshan, Wuxi, where no fungicides were applied and dormant pruning was employed for disease management. Two types of necrotic symptoms were observed: one in which the necrotic tissue at the base of the shoot often became sunken, and another characterized by necrotic tissue with rings. To isolate putative pathogens, shoot tissue with characteristic symptoms of both diseases were randomly collected from 52 trees (Prunus persica 'Baifeng', 'Hujingmilu', 'Xinbaifeng', and 'Zhaohui') in three orchards. The disease occurred initially on peach buds that turned black. Subsequently, reddish-brown cankers developed on the nodes at the bases of shoots with or without rings, and resulted in shoot blight (Fig. 1).

In this study, 202 twigs with necrotic symptoms without rings and 157 necrotic twigs with rings were collected. After surface disinfestation of branch tissues with $95 \%$ ethanol for $30 \mathrm{~s}$ and $0.3 \% \mathrm{H}_{2} \mathrm{O}_{2}$ for $1 \mathrm{~min}$, followed by rinsing twice with sterilized water, infected tissues (approximately $0.25 \mathrm{~cm}^{2}$ ) were excised and plated on potato dextrose agar (PDA) plates containing lactic acid $(100 \mu \mathrm{l}$ of lactic acid per $100 \mathrm{ml}$ of medium). Cultures were incubated at $25^{\circ} \mathrm{C}$ in the dark until fungal mycelia were observed. Each isolate was further purified by subculturing a single conidium. 
Morphological identification and characterization. Isolates were identified tentatively based on colony morphology and conidial characteristics described in previous studies (Bai et al. 2015; Phillips et al. 2005; Wang et al. 2011). Briefly, a purified isolate was established from a 7-day-old mycelial plug (4 $\mathrm{mm}$ in diameter) placed in the center of a 90-mm PDA Petri dish. Cultures were incubated at $25^{\circ} \mathrm{C}$ with a 12 -h photoperiod for 12 days until pycnidia formation. The colony appearance was recorded daily. Conidia oozing out of pycnidia were picked up with sterilized toothpicks and placed in a drop of sterilized water on microscope slides under the microscope (Nikon Eclipse E600 FN; Nikon). Fifty conidia were measured and then photographed with the SPOT program (version 4.6; Diagnostic Instruments, Inc.). Conidial color and shape were also recorded.
These measurements were done in triplicate on three separate cultures of each isolate.

Effect of temperature on mycelial growth. Isolates were transferred to PDA from plates stored at $4{ }^{\circ} \mathrm{C}$, then incubated at $25^{\circ} \mathrm{C}$ for 5 days. Mycelial plugs ( $4 \mathrm{~mm}$ in diameter) from the growing edge of these cultures were then transferred to the middle of 90-mm PDA plates. The plates were incubated in the dark at 5, 10, 15, 20, 25, 30, and $35^{\circ} \mathrm{C}$. Colony diameter was measured in two perpendicular directions on each plate after 10 days of incubation. For each isolate, three plates were inoculated and the experiment was conducted three times.

DNA extraction, amplification, and multigene phylogenetic analysis. Genomic DNA from arbitrarily selected fungal isolates
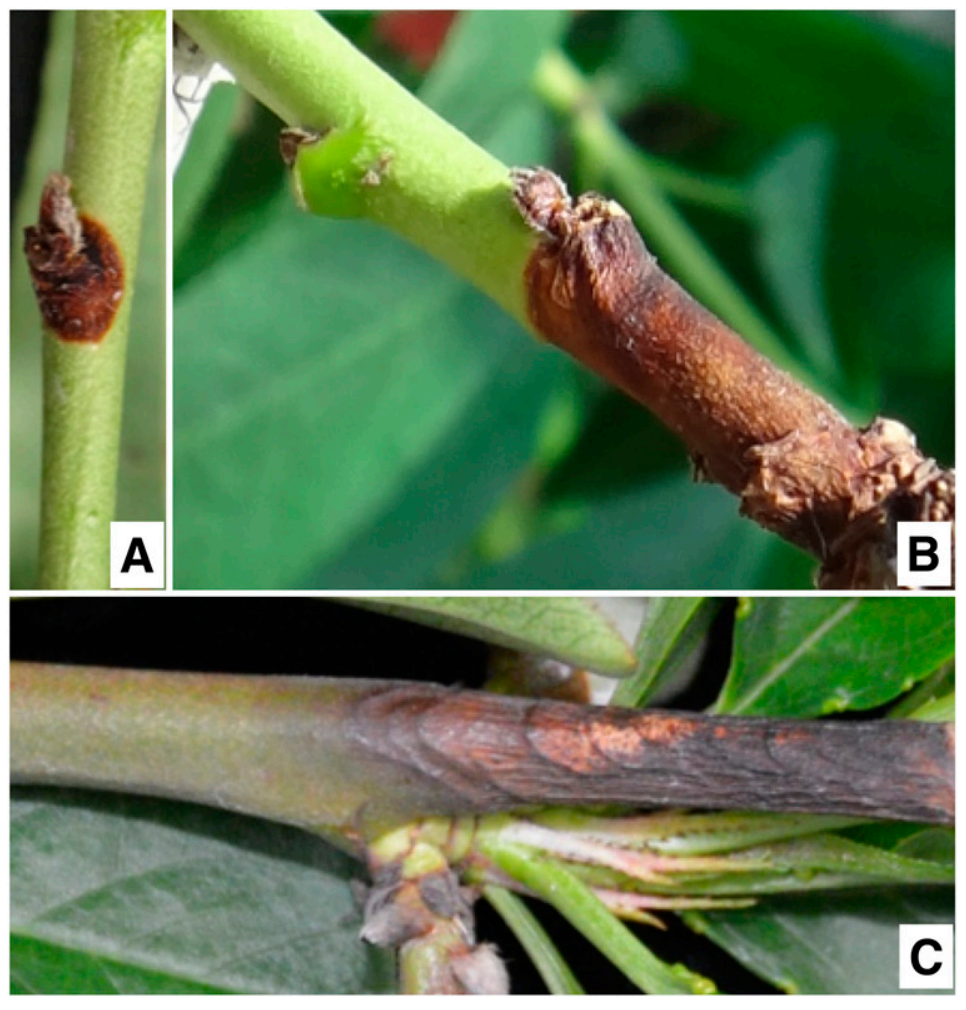

C

Fig. 1. Typical symptoms of peach shoot blight in peach orchard in Yangshan, China. A, Initial necrotic symptoms on peach buds; B, necrotic shoot lesion without rings; C, necrotic shoot lesion with rings; and $\mathbf{D}$, shoot blight symptoms on shoots.

Table 1. Phomopsis amygdali and Botryosphaeria dothidea isolates from peach (Prunus persica) orchards in Yangshan, Jiangsu Province, China used in this study ${ }^{\mathrm{a}}$

\begin{tabular}{|c|c|c|c|c|c|c|}
\hline \multirow[b]{2}{*}{ Isolate } & \multirow[b]{2}{*}{ Village } & \multirow[b]{2}{*}{ Host cultivar } & \multirow[b]{2}{*}{ Year } & \multicolumn{3}{|c|}{ GenBank accession number } \\
\hline & & & & ITS & EF1- $\alpha$ & $\overline{\beta-T u b u l i n}$ \\
\hline \multicolumn{7}{|c|}{ Phomopsis amygdali } \\
\hline SL-8-1 & Runyang & Baifeng & 2014 & MG82283 & MG82296 & MG82309 \\
\hline YH-22 & Taohuayuan & Hujingmilu & 2014 & MG82284 & MG82297 & MG82310 \\
\hline YH-37 & Taohuayuan & Hujingmilu & 2014 & MG82285 & MG82298 & MG82311 \\
\hline FZ-1 & Fushan & Zhaohui & 2014 & MG82286 & MG82299 & MG82312 \\
\hline KY-2 & Runyang & Xinbaifeng & 2015 & MG82287 & MG82300 & MG82313 \\
\hline KYB-15 & Fushan & Baifeng & 2015 & MG82288 & MG82301 & MG82314 \\
\hline \multicolumn{7}{|c|}{ Botryosphaeria dothidea } \\
\hline TM-11 & Fushan & Baifeng & 2014 & MG82289 & MG82302 & MG82315 \\
\hline YH-31 & Fushan & Baifeng & 2014 & MG82290 & MG82303 & MG82316 \\
\hline YH-45 & Runyang & Baifeng & 2014 & MG82291 & MG82304 & MG82317 \\
\hline $\mathrm{YH}-40$ & Taohuayuan & Baifeng & 2014 & MG82292 & MG82305 & MG82318 \\
\hline $\mathrm{ZM}-1$ & Fushan & Xinbaifeng & 2015 & MG82293 & MG82306 & MG82319 \\
\hline $\mathrm{ZM}-8$ & Runyang & Hujingmilu & 2015 & MG82294 & MG82307 & MG82320 \\
\hline ZM-9 & Taohuayuan & Zhaohui & 2015 & MG82295 & MG82308 & MG82321 \\
\hline
\end{tabular}

\footnotetext{
${ }^{\text {a }}$ This table includes the geographical origin (Village), year of isolation, the peach cultivar from which isolates were recovered, and GenBank accession numbers
} for the internal transcribed spacer (ITS), elongation factor subunit 1- $\alpha(E F 1-\alpha)$, and $\beta$-tubulin gene sequences generated for each isolate. 
SL-8-1, YH-22, YH-37, FZ-1, KY-2, KYB-15, TM-11, YH-31, YH45, YH-40, ZM-1, ZM-8, and ZM-9 (Table 1) was extracted using the TIANamp Fungal DNA Kit (TIANamp BIOTECH) according to the manufacturer's directions. Three regions, including the ribosomal internal transcribed spacer (ITS; including a partial $18 \mathrm{~S}$ ribosomal RNA [rRNA] gene, ITS1, 5.8S rRNA gene, ITS2, and partial $28 \mathrm{~S}$ rRNA gene), $\beta$-tubulin, and the translational elongation factor subunit $1-\alpha$ gene $(E F 1-\alpha)$, were amplified by polymerase chain reaction (PCR) using the primer pairs ITS1/ITS4 (White et al. 1990), Bt2a/Bt2b (Glass and Donaldson 1995), and EF1-728F/EF1-986R (Carbone and Kohn 1999) (Table 2).

Each 50- $\mu$ l amplification reaction contained $1 \mu l$ of template DNA $(5 \mathrm{ng}), 5 \mu \mathrm{l}$ of $10 \times$ PCR buffer, $1 \mu \mathrm{l}$ each of PCR primer $(10 \mathrm{mM})$, $1 \mu \mathrm{l}$ of dNTP mix (10 mM), $6 \mu \mathrm{l}$ of $\mathrm{MgCl}_{2}(25 \mathrm{mM}), 2.5 \mathrm{U}$ of Taq DNA polymerase (TaKaRa), and $34 \mu \mathrm{l}$ of sterilized water. PCR was performed using an Applied Biosystems 2720 thermal cycler (Applied Biosystems) with the following thermal profile: $5 \mathrm{~min}$ at $95^{\circ} \mathrm{C}$ for initial denaturation, followed by 30 cycles of denaturation at $95^{\circ} \mathrm{C}$ for $30 \mathrm{~s}$, annealing for $30 \mathrm{~s}$ at the primer-pair-specific annealing temperature (Table 2), and extension at $72^{\circ} \mathrm{C}$ for $30 \mathrm{~s}$. A final extension was performed at $72^{\circ} \mathrm{C}$ for $10 \mathrm{~min}$. Following this initial PCR, amplicons were treated with AxyPrepPCR cleanup reagent (Axygen) according to the manufacturer's instructions. Amplicons were then sent to Yidao Life for direct Sanger sequencing (Table 2).

The GenBank accession numbers of the sequences generated in this study are included in Table 1. Phylogenetic trees were generated using MEGA 5.10 (Tamura et al. 2011) with maximum-likelihood, minimum evolution. Gaps or undetermined data in the alignment were excluded when site coverage was below $95 \%$. Confidence levels of the branching points were determined using 1,000 bootstrap replicates.

Pathogenicity tests. Representative isolates collected from infected peach trees in this study were grown on PDA at $25^{\circ} \mathrm{C}$ for 5 days prior to inoculation. Pathogenicity tests were conducted on 1-year-old twigs of peach cultivar Baifeng. Twigs were wounded with a sterilized blade, and a 4-mm-diameter mycelium agar plug was placed on the wound and wrapped with Parafilm to maintain high humidity for 14 days postinoculation (dpi). As a negative control, five twigs were inoculated with 4-mm-diameter fresh PDA agar plugs. All inoculated twigs were planted in 25-liter plastic pots with a mix of vermiculite and soil $(1: 1, \mathrm{vol} / \mathrm{vol})$ and maintained in a CLIMACELL growth chamber (MMM Medcenter Einrichtungen $\mathrm{GmbH}$ ) at $28^{\circ} \mathrm{C}$ (day) and $18^{\circ} \mathrm{C}$ (night), with five twigs per fungal isolate. The symptoms and disease incidences were recorded at $14 \mathrm{dpi}$.

Determination of the possible inoculum sources. Two orchards located in Runyang and Fushan villages were sampled on 2 February 2016 in order to determine the inoculum sources of Phomopsis amygdali and $B$. dothidea. Three possible overwintering sites (peach buds, cankers, and necrotic twigs) were collected. Fifty samples from each potential inoculum source were collected from orchards and taken to the laboratory for analysis. Bud, canker, and necrotic twig samples were used to extract fungal genomic DNA using the TIANamp Fungal DNA Kit (TIANamp BIOTECH) according to the manufacturer's directions. DNA $(1 \mu \mathrm{l})$ was used as template for PCR detection using the primer pairs histone H3-F/histone H3-R (for P. amygdali) (Wang et al. 2017) or FaF/Bt2b (for B. dothidea) (Wang 2012).

Statistical analysis. Lesion length measurements of all necrotic shoots were analyzed statistically using SPSS 14.0 (SPSS Inc.). The one-way Student's $t$ test $(P=0.05)$ was used to determine the significance of differences in lesion length among $P$. amygdali and B. dothidea isolates.

\section{Results}

Isolation and cultural characteristics of causal agents of peach shoot blight. In total, 202 isolates showing cultural and conidial morphology typical of Phomopsis spp. on PDA plates were classified into group 1 . They formed gray colonies with thin mycelia that produced aerial hyphal over rings (Fig. 2). Spherical, black pycnidia were scattered over the colony after 12 days of incubation. The $\alpha$-conidia of the six isolates (SL-8-1, KY-2, YH-22, YH-37, FZ-1, and KYB-15) tested were fusiform, hyaline, single-celled, and aseptate, with lengths ranging from 4.60 to $10.20 \mu \mathrm{m}$ and widths from 1.85 to $4.31 \mu \mathrm{m}$. The $\beta$-conidia of the six isolates were filiform, hyaline, single-celled, and aseptate, with lengths ranging from 12.11 to 37. $91 \mu \mathrm{m}$ and widths from 0.99 to $2.72 \mu \mathrm{m}$. These characteristics (Table 3) matched those described for P. amygdali (Smit et al. 1996).

Group 2 included 156 isolates that displayed cultural and conidial morphology typical of Botryosphaeria spp. on PDA plates. They formed white to olive-green colonies that developed moderate aerial hyphae, and conidia of the seven isolates (TM-11, ZM-1, ZM-8, ZM9, YH-31, YH-45, and YH-40) were fusiform, hyaline, and aseptate (Fig. 2), with lengths ranging from 18.40 to $29.70 \mu \mathrm{m}$ and widths from 4.80 to $10.80 \mu \mathrm{m}$. These characteristics (Table 4) matched those described for B. dothidea (Phillips et al. 2005).

Other fungal species from genera such as Alternaria (16 isolates) and Fusarium (16 isolates) isolated from diseased peach samples were not included in this study.

Group 1

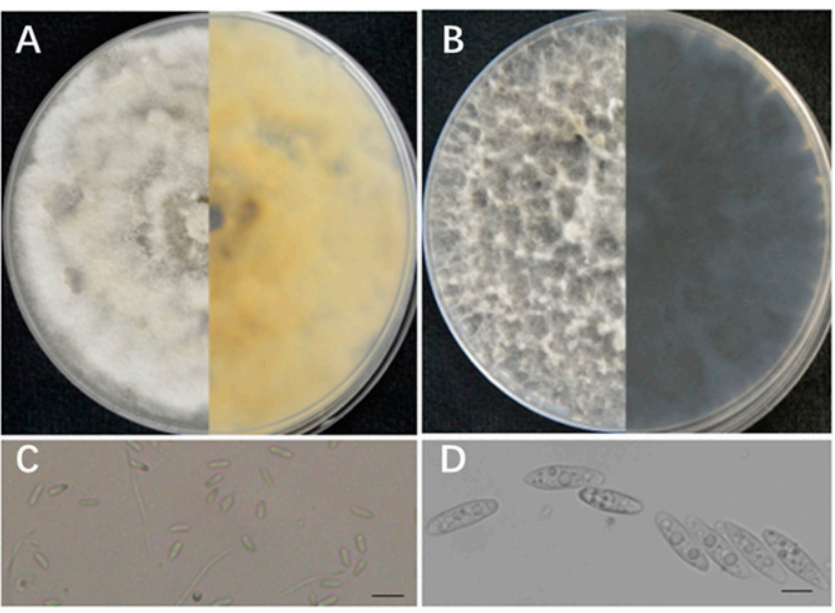

Fig. 2. Colony and conidial morphologies of fungi isolated from infected peach tissues. Photos show representative morphologies of colonies and conidia of group 1 isolate (SL-8-1) of Phomopsis amygdali and group 2 isolate (TM-11) of Botryosphaeria dothidea. A and $\mathbf{B}$, Colony appearance of representative isolates that were cultured on potato dextrose agar, with images taken 12 days after plating; and $\mathbf{C}$ and $\mathbf{D}$, at the bottom, scale bar $=10 \mu \mathrm{m}$

Table 2. Multilocus sequence analysis primers used to characterize fungal isolates recovered from peach shoot blight-infected tissues in this study

\begin{tabular}{llccc}
\hline Primer & \multicolumn{1}{c}{ Sequence $\left(\mathbf{5}^{\prime} \mathbf{-} \mathbf{3}^{\prime}\right)$} & Size $(\mathbf{b p})$ & Annealing temperature $\left({ }^{\circ} \mathbf{C}\right)$ & Reference \\
\hline ITS1 & TCCGTAGGTGAACCTGCGG & 600 & 55 & White et al. 1990 \\
ITS4 & TCCTCCGCTTATTGATATGC & $\ldots$ & $\ldots$ & $\ldots$ \\
EF-728F & CATCGAGAAGTTCGAGAAGG & 350 & 58 & Carbone and Kohn 1999 \\
EF-986R & TACTTGAAGGAACCCTTACC & $\ldots$ & $\ldots$ & $\ldots$ \\
Bt2a & GGTAACCAAATCGGTGCTGCTTTC & 450 & 55 & Glass and Donaldson 1995 \\
Bt2b & ACCCTCAGTGTAGTGACCCTTGGC & $\ldots$ & $\ldots$ & $\ldots$ \\
\hline
\end{tabular}


Phylogenetic analyses. Genes from 13 isolates were sequenced to confirm their identities (Table 5). PCR amplification of the ITS, $\mathrm{EF} 1-\alpha$, and $\beta$-tubulin gene regions yielded amplicons of approximately $0.6,0.35$, and $0.4 \mathrm{~kb}$, respectively. These sequences were deposited in GenBank (Table 1). The three loci were concatenated and a phylogenetic tree was generated. $P$. amygdali and $B$. dothidea isolates formed two strongly supported clades that clustered together with $P$. amygdali strain CBS 120840 and B. dothidea strain SZ-422, respectively. These clades were supported by $100 \%$ bootstrap values, which confirmed pathogen identification (Fig. 3).

Comparison of isolation frequency of $P$. amygdali and $B$. dothidea isolates. Samples were collected twice (spring and autumn) in both 2014 and 2015. Quantitative differences in isolation frequencies of fungal isolates were obtained in four sample collections during this study (Fig. 4). For two sample collections in March, significantly $(P<0.05)$ more $P$. amygdali $(69.57$ and $79.35 \%$ for 2014 and 2015, respectively) was isolated than B. dothidea (30.43 and $20.65 \%$ for 2014 and 2015 , respectively). In contrast, for two sample collections in July, significantly $(P<0.05)$ more $B$. dothidea (61.45 and $63.74 \%$ for 2014 and 2015, respectively) was isolated than P. amygdali (38.55 and $36.26 \%$ for 2014 and 2015, respectively).

Interestingly, $P$. amygdali was only isolated from twigs with necrotic symptoms, while $B$. dothidea was only isolated from 1 of 202 samples with only necrotic symptoms (Table 5 ). In contrast, $B$. dothidea was isolated from all twigs with ring symptoms, while $P$. amygdali was only isolated in 2 of 157 samples with necrotic lesions with rings (Table 5).

Comparison of virulence among $P$. amygdali and $B$. dothidea isolates. Of the isolates collected from symptomatic Baifeng peach twigs in Yangshan, three representative isolates of $P$. amygdali and $B$. dothidea were used in virulence assays. All $13 P$. amygdali and $B$. dothidea isolates were pathogenic on peach and produced brown necrotic lesions by 1 week postinoculation. In contrast, $B$. dothidea isolates induced necrotic lesions with rings (Figs. 5 and $6)$. Three $B$. dothidea isolates induced significantly longer lesions than those induced by $P$. amygdali isolates $(P<0.05)$. The symptoms induced by both species matched those observed under natural conditions in peach orchards. As expected, no lesions developed on control branches inoculated with fresh PDA agar plugs.

Effect of temperature on mycelial growth. All isolates of each pathogen had identical or similar growth rates (Fig. 7). Both pathogens grew on PDA at 10 to $30^{\circ} \mathrm{C}$ but $P$. amygdali isolates failed to grow at $5^{\circ} \mathrm{C}$. The maximum growth rate was observed at 25 and $30^{\circ} \mathrm{C}$ for $P$. amygdali and $B$. dothidea, respectively. The pathogens grew at significantly different $(P<0.05)$ rates; $B$. dothidea grew faster than $P$. amygdali at 5,30 , and $35^{\circ} \mathrm{C}$ and slower than $P$. amygdali at 15 and $20^{\circ} \mathrm{C}$.

Detection of possible inoculum sources. Using the histone $\mathrm{H} 3-\mathrm{F} /$ histone H3-R primers, 36 of 50 buds, 13 of 50 cankers, and 10 of 50 necrotic twigs were positive for $P$. amygdali by PCR assay (Table 6). Using the FaF/Bt $2 \mathrm{~b}$ primers, 22 of 50 buds, 5 of 50 cankers, and 4 of 50 necrotic twigs were detected $B$. dothidea by PCR assay (Table 6).

\section{Discussion}

Our results showed that the shoot blight of peach trees observed in Yangshan, China was caused by $P$. amygdali and B. dothidea. Comparison of disease symptoms, conidial morphology, and cultural characteristics, as well as analyses of nucleotide sequences of three genes, allowed these fungi to be clearly differentiated. Results of this study indicated that peach shoot blight in Yangshan was primarily caused by $P$. amygdali, which is consistent with a previous report (Ji et al. 2013). However, our study revealed that $B$. dothidea is also capable of causing peach shoot blight symptoms in Yangshan. This finding is important for understanding the epidemiology of peach shoot blight in Yangshan and providing a basis for developing effective strategies for disease management.

Results of previous studies suggest that many members of the genus Botryosphaeria are weak or opportunistic pathogens, as well as common endophytes of woody plants (Pérez et al. 2010; Slippers and Wingfield 2007). B. dothidea has a worldwide distribution and is capable of infecting numerous plant species (Lazzizera et al. 2008; Phillips et al. 2007; Tang et al. 2012; Thomidis et al. 2011). Most Botryosphaeria spp. are considered to be latent plant pathogens that cause dieback, cankers, gummosis, leaf spots, or fruit rots on a number of woody plants, including pear, grape, mango, olive, eucalyptus, maple, oak, and almond (Phillips et al. 2013; Zhai et al. 2014). According to a previous study, $B$. dothidea causes perennial cankers in peach tree trunks, branches, and shoots (Weaver 1974).

Our virulence assays showed that $B$. dothidea isolates induced necrotic lesions with rings, whereas $P$. amygdali isolates only induced

Table 4. Morphological characteristics of the representative isolates of Botryosphaeria dothidea in this study

\begin{tabular}{lccc}
\hline & \multicolumn{2}{c}{ Conidial size $(\boldsymbol{\mu m})^{\mathbf{a}}$} & \\
\cline { 2 - 3 } Isolate & Length & Width & \\
\hline TM-11 & $18.40-27.78$ & $5.23-10.80$ & $23.23 \pm 2.72 \times 6.84 \pm 0.77$ \\
ZM-1 & $20.09-28.88$ & $4.80-10.01$ & $23.08 \pm 1.74 \times 6.06 \pm 0.76$ \\
ZM-8 & $19.07-29.70$ & $4.97-10.55$ & $22.78 \pm 2.54 \times 6.36 \pm 0.56$ \\
ZM-9 & $18.80-28.38$ & $5.03-10.65$ & $23.44 \pm 2.63 \times 6.14 \pm 0.68$ \\
YH-31 & $18.89-27.88$ & $5.20-10.73$ & $23.23 \pm 2.52 \times 6.51 \pm 0.71$ \\
YH-45 & $19.40-28.43$ & $4.98-10.30$ & $22.92 \pm 2.42 \times 6.64 \pm 0.57$ \\
YH-40 & $19.12-29.66$ & $5.02-10.59$ & $23.08 \pm 2.04 \times 6.46 \pm 0.66$ \\
\hline
\end{tabular}

Table 5. Frequency of Phomopsis amygdali or Botryosphaeria dothidea isolation from peach twigs displaying shoot blight symptoms in Yangshan, China in 2014 and 2015

\begin{tabular}{lcc}
\hline & \multicolumn{2}{c}{ Fungus (positive/total) } \\
\cline { 2 - 3 } Symptoms & P. amygdali & B. dothidea \\
\hline Necrosis without rings & $202 / 202$ & $1 / 202$ \\
Necrosis with rings & $2 / 157$ & $156 / 157$ \\
\hline
\end{tabular}

Table 3. Morphological characteristics of the representative isolates of Phomopsis amygdali in this study

\begin{tabular}{|c|c|c|c|c|c|c|}
\hline \multirow[b]{3}{*}{ Isolate } & \multicolumn{4}{|c|}{ Conidial size $(\mu \mathrm{m})^{\mathbf{a}}$} & & \\
\hline & \multicolumn{2}{|c|}{$\alpha$-Conidia } & \multicolumn{2}{|c|}{$\beta$-Conidia } & \multicolumn{2}{|c|}{ Mean \pm SD $(\mu \mathrm{m})^{b}$} \\
\hline & Length & Width & Length & Width & $\alpha$-Conidia & $\beta$-Conidia \\
\hline SL-8-1 & $4.62-10.20$ & $2.65-4.31$ & $12.11-34.19$ & $0.99-1.56$ & $7.34 \pm 1.2 \times 3.14 \pm 0.25$ & $29.21 \pm 5.98 \times 1.06 \pm 0.21$ \\
\hline KY-2 & $4.60-9.67$ & $1.85-4.30$ & $18.67-37.75$ & $1.11-1.76$ & $7.35 \pm 0.71 \times 2.62 \pm 0.32$ & $30.22 \pm 2.65 \times 1.33 \pm 0.15$ \\
\hline YH-22 & $4.71-9.55$ & $1.87-4.01$ & $19.89-37.89$ & $1.05-2.69$ & $7.65 \pm 0.89 \times 2.65 \pm 0.39$ & $30.12 \pm 4.65 \times 1.23 \pm 0.18$ \\
\hline YH-37 & $4.60-9.67$ & $1.89-4.26$ & $18.67-37.75$ & $1.10-1.74$ & $7.33 \pm 0.77 \times 2.72 \pm 0.32$ & $30.20 \pm 2.05 \times 1.30 \pm 0.11$ \\
\hline FZ-1 & $4.68-9.45$ & $1.89-4.12$ & $19.79-37.89$ & $1.05-2.69$ & $7.65 \pm 0.91 \times 2.69 \pm 0.44$ & $30.15 \pm 4.60 \times 1.27 \pm 0.12$ \\
\hline KYB-15 & $4.66-9.60$ & $1.91-4.11$ & $19.82-37.91$ & $1.09-2.72$ & $7.64 \pm 0.86 \times 2.78 \pm 0.49$ & $30.16 \pm 4.21 \times 1.28 \pm 0.20$ \\
\hline
\end{tabular}

a Numbers indicate minimum and maximum lengths and widths, respectively, of 50 conidia recorded from each selected isolate. Significance at $P=0.05$ level. ${ }^{\mathrm{b}} \mathrm{SD}=$ standard deviation. 
necrotic lesions. We observed a correlation between the fungal species and disease symptom produced on infection (Tables 3 and 4), suggesting that distinctive symptoms were produced by $P$. amygdali and $B$. dothidea. In other words, $P$. amygdali caused shoot blight symptoms typified by necrotic lesions, whereas $B$. dothidea caused shoot blight symptoms typified by necrotic lesions with ring symptoms. It is notable that $P$. amygdali and $B$. dothidea were recovered simultaneously from 2 of 359 peach twig samples collected from orchards in Yangshan (Tables 3 and 4), indicating that peach twigs could be coinfected with both pathogens. This conclusion was also supported by PCR detection of both pathogens simultaneously in 11 peach buds (Table 6 ).

In this study, we sampled three orchards in Yangshan on 7 March 2014, 23 July 2014, 20 March 2015, and 20 July 2015. Interestingly, the frequency of $B$. dothidea detection was higher than that of $P$. amygdali in autumn 2014 and 2015 but lower than that of $P$. amygdali in the spring of these 2 years (Fig. 4). The fact that the frequency of pathogen isolation differed at different sampling dates suggests that pathogen infection may be affected by temperature. In comparing the growth rates of these two pathogens, we observed

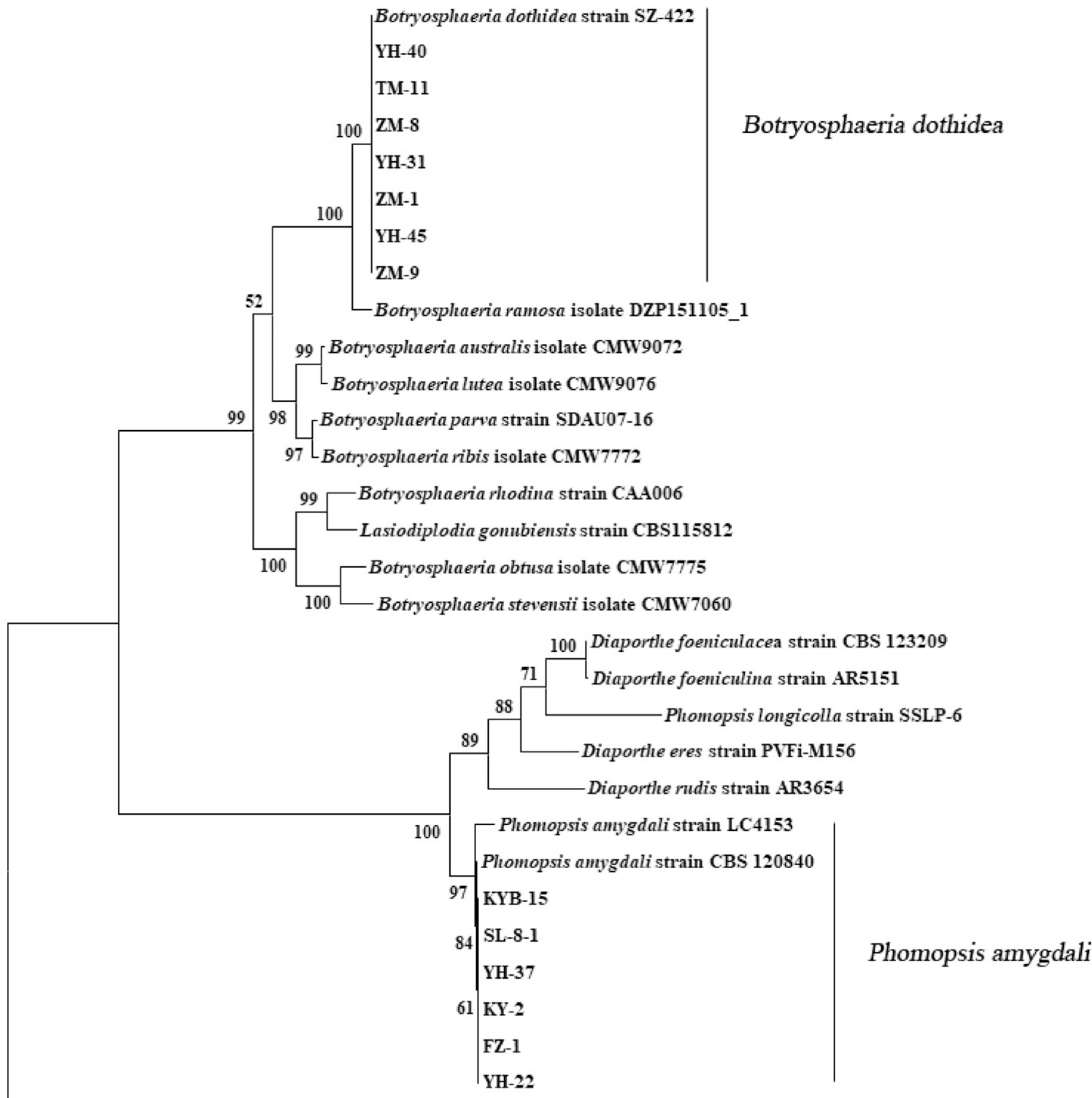

Alternaria alternata strain CBS 916.96

0.1

Fig. 3. Maximum-likelihood phylogenetic analysis of isolates obtained from peach shoot blight samples collected in Yangshan, China along with Phomopsis amygdali and Botryosphaeria dothidea isolates registered in the GenBank database on the basis of concatenated sequences of the internal transcribed spacer, $\beta$-tubulin, and translational elongation factor subunit $1-\alpha$ genes. 


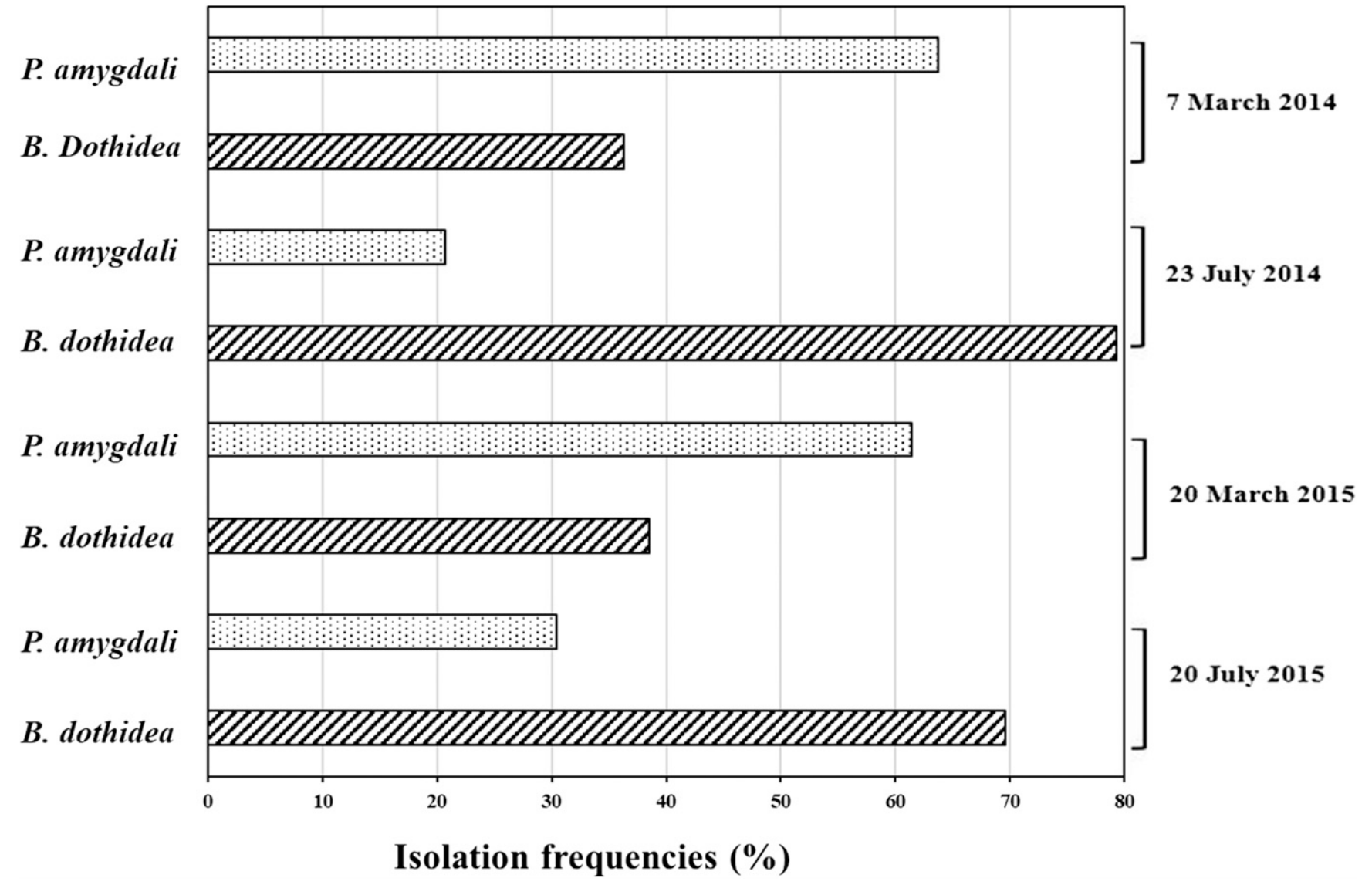

Fig. 4. Average percent incidence of Phomopsis amygdali and Botryosphaeria dothidea isolated from symptomatic peach twigs collected in Yangshan, China in 2014 and 2015.

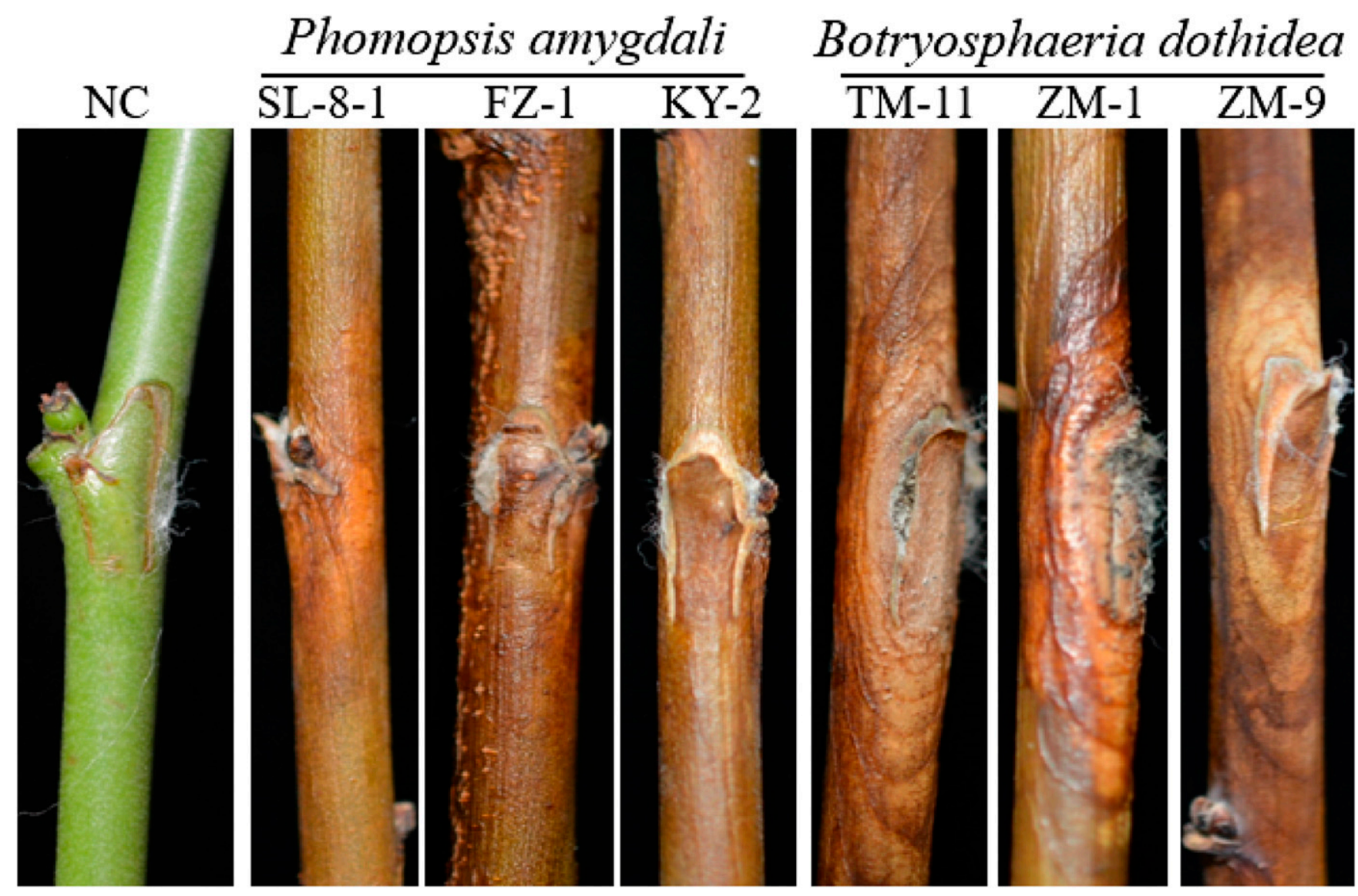

Fig. 5. Shoot blight symptoms induced by representative isolates of Phomopsis amygdali and Botryosphaeria dothidea in this study. Symptoms induced by inoculation of wounded, attached peach twigs with potato dextrose agar (PDA) plug containing fungal mycelia; NC = inoculation with 4-mm-diameter mycelium-free PDA agar plugs. Representative symptoms were photographed at 14 days postinoculation. 
a significant difference in spring (usually $<15^{\circ} \mathrm{C}$ ) and summer (usually $>25^{\circ} \mathrm{C}$ ) in Yangshan.

Results of this study showed that the frequencies of detection of both $P$. amygdali and $B$. dothidea from buds were significantly higher for other tissue types or organs. This suggests that the buds may be the main sites of infection for these two fungi, which is consistent with the conclusion that the disease is initiated by fungal invasion of buds (Melanson et al. 2002; Udayanga et al. 2011). Thus, under natural field conditions, peach shoot blight develops initially as necrosis on the current season's shoots, centered around the

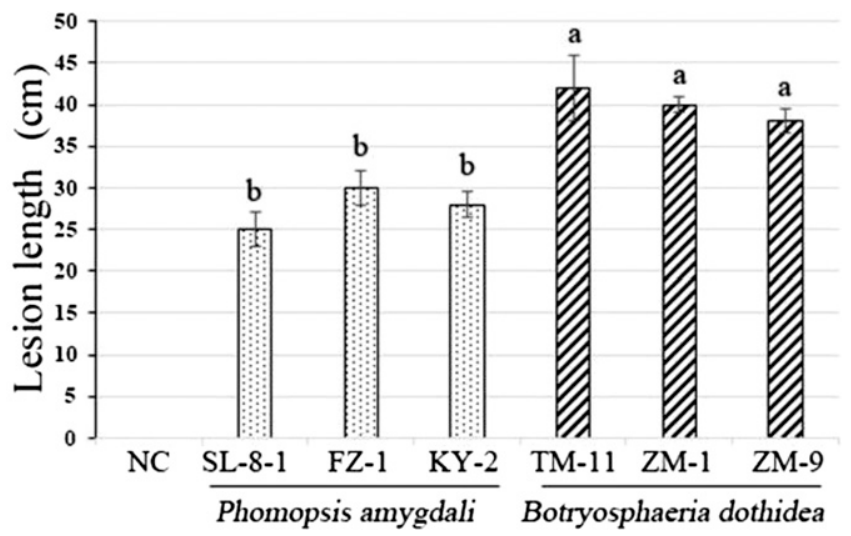

Fig. 6. Mean peach shoot blight lesion lengths induced by representative Phomopsis amygdali and Botryosphaeria dothidea isolates. Results represent three replicates of inoculated twigs measured at 14 days postinoculation; $\mathrm{NC}=$ inoculation with 4-mmdiameter mycelium-free PDA agar plugs. Data were analyzed with SPSS Statistics 14.0 (SPSS Inc.) by one-way analysis of variance, and means were compared using Tukey's test at a significance level of $P=0.05$. Different letters over the bars indicate the significant difference at $P=0.05$. buds (Fig. 1). Under appropriate environmental conditions, necrotic lesions expand rapidly, disrupt vascular tissues, and cause shoots to wilt. This would explain why cankers are centrally positioned on the buds at the base of shoots in the orchards.

Peach tree diseases with symptoms similar to those of peach shoot blight have been reported in different regions, with only $P$. amygdali as the causal agent (Dai et al. 2012; Farr et al. 1999; Lalancette and Polk 2000). In particular, the pathogen that caused peach shoot blight in Yangshan was referred to by Ji et al. (2013) as P . amygdali. However, our results differ from a previous study. The present work clearly showed that, in addition to $P$. amygdali, isolates of $B$. dothidea were pathogenic on peach twigs and induced canker symptoms that resembled those observed in the field. It was notable that the $B$. dothidea isolates displayed higher levels of virulence than the $P$. amygdali isolates on Baifeng peach twigs. These results suggest that future research on disease management should focus on $B$. dothidea in addition to $P$. amygdali in Yangshan.

Table 6. Frequency of detection of Phomopsis amygdali and Botryosphaeria dothidea in peach shoot blight tissues collected in Yangshan, China by polymerase chain reaction between 2014 and 2015

\begin{tabular}{lcc}
\hline & \multicolumn{2}{c}{ Detection frequency (positive/total) } \\
\cline { 2 - 3 } Tissues & $\boldsymbol{P .}$ amygdali & $\boldsymbol{B}$. dothidea \\
\hline Discolored buds & $36 / 50$ & $22 / 50$ \\
Cankers & $13 / 50$ & $5 / 50$ \\
Necrotic twigs & $10 / 50$ & $4 / 50$ \\
Asymptomatic buds & $11 / 50$ & $8 / 50$ \\
Discolored trunks & $0 / 18$ & $5 / 18$ \\
\hline
\end{tabular}

${ }^{a}$ Numbers indicate mean frequencies from different sites calculated by the statistical analysis. Data were analyzed with SPSS Statistics 14.0 (SPSS Inc.).

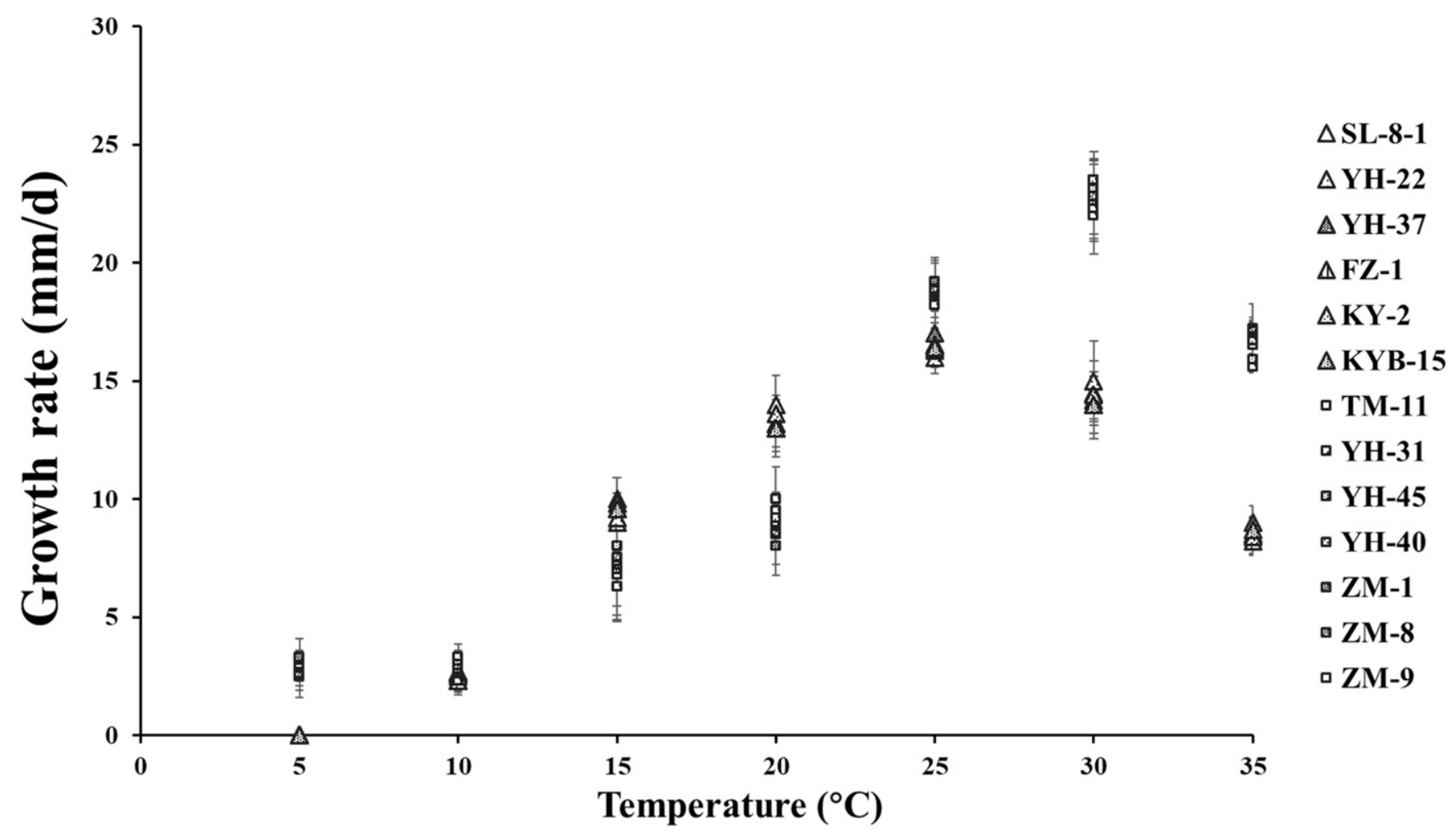

Fig. 7. Growth rates of three representative isolates of Phomopsis amygdali and Botryosphaeria dothidea recovered from peach shoot blight samples in Yangshan, China. 


\section{Acknowledgments}

We thank R. R. Walcott, University of Georgia, United States, for critical revisions for the manuscript.

\section{Literature Cited}

Bai, Q., Zhai, L., Chen, X., Hong, N., Xu, W., and Wang, G. 2015. Biological and molecular characterization of five Phomopsis species associated with pear shoot canker in China. Plant Dis. 99:1704-1712.

Carbone, I., and Kohn, L. M. 1999. A method for designing primer sets for speciation studies in filamentous ascomycetes. Mycologia 91:553-556.

Chen, J., and Tian, Y. 2016. Predicament of Yangshan juicy Honey peach industrialization. N. W. China 13:54. (In Chinese)

Dai, F. M., Zeng, R., and Lu, J. P. 2012. First report of twig canker on peach caused by Phomopsis amygdali in China. Plant Dis. 96:288-289.

Dai, R. 1998. Preliminary study on the Yangshan juicy Honey peach industrialization. Jiangsu Greening 4:9-10. (In Chinese)

Farr, D. F., Castlebury, L. A., and Pardo-Schultheiss, R. A. 1999. Phomopsis amygdali causes peach shoot blight of cultivated peach trees in the Southeastern United States. Mycologia 91:1008-1015.

Glass, N. L., and Donaldson, G. C. 1995. Development of primer sets designed for use with the PCR to amplify conserved genes from filamentous ascomycetes. Appl. Environ. Microbiol. 61:1323-1330.

Ji, Z., Dai, H., Jin, W., Song, H., Zhang, H., Jin, J., Xiong, C., and Xu, J. 2013. Identification of the pathogen causing shoot blight of peach trees. J. Yangzhou Univ. 4:94-98. (In Chinese)

Lalancette, N., and Polk, D. F. 2000. Estimating yield and economic loss from constriction canker of peach. Plant Dis. 84:941-946.

Lazzizera, C., Frisullo, S., Alves, A., and Phillips, A. J. L. 2008. Morphology, phylogeny and pathogenicity of Botryosphaeria and Neofusicoccum species associated with drupe rot of olives in southern Italy. Plant Pathol. 57: 948-956.

Melanson, D. L., Rawnsley, B., and Scheper, R. W. A. 2002. Molecular detection of Phomopsis, taxa 1 and 2 in grapevine canes and buds. Australas. Plant Pathol. 31:67-73.

Pérez, C. A., Wingfield, M. J., Slippers, B., Altier, N. A., and Blanchette, R. A. 2010. Endophytic and canker-associated Botryosphaeriaceae occurring on non-native Eucalyptus and native Myrtaceae trees in Uruguay. Fungal Divers. 41:53-69.

Phillips, A. J. L., Alves, A., Abdollahzadeh, J., Slippers, B., Wingfield, M. J., Groenewald, J. Z., and Crous, P. W. 2013. The Botryosphaeriaceae: Genera and species known from culture. Stud. Mycol. 76:51-167.

Phillips, A. J. L., Crous, P. W., and Alves, A. 2007. Diplodia seriata, the anamorph of "Botryosphaeria" obtusa. Fungal Divers. 25:141-155.
Phillips, A. J. L., Rumbos, I. C., Alves, A., and Correia, A. 2005. Morphology and phylogeny of Botryosphaeria dothidea causing fruit rot of olives. Mycopathologia 159:433-439.

Puterka, G. J., Scorza, R., and Brown, M. W. 1993. Reduced incidence of lesser peachtree borer and Leucostoma canker in peach-almond hybrids. J. Am. Soc. Hortic. 118:864-867.

Slippers, B., and Wingfield, M. J. 2007. Botryosphaeriaceae as endophytes and latent pathogens of woody plants: Diversity, ecology and impact. Fungal Biol. Rev. 21:90-106.

Smit, W. A., Viljoen, C. D., Wingfield, B. D., Wingfield, M. J., and Calitz, F. J. 1996. A new canker disease of apple, pear, and plum rootstocks caused by Diaporthe ambigua in South Africa. Plant Dis. 80:1331-1335.

Tamura, K., Peterson, D., Peterson, N., Stecher, G., Nei, M., and Kumar, S. 2011. MEGA5: Molecular Evolutionary Genetics Analysis using maximum likelihood, evolutionary distance, and maximum parsimony methods. Mol. Biol. Evol. 28:2731-2739.

Tang, W., Ding, Z., Zhou, Z. Q., Wang, Y. Z., and Guo, L. Y. 2012. Phylogenetic and pathogenic analyses show that the causal agent of apple ring rot in China is Botryosphaeria dothidea. Plant Dis. 96:486-496.

Thomidis, T., Michailides, T. J., and Exadaktylou, E. 2011. Neofusicoccum parvum associated with fruit rot and shoot blight of peaches in Greece. Eur. J. Plant Pathol. 131:661-668.

Udayanga, D., Liu, X., McKenzie, E. H. C., Chukeatirote, E., Bahkali, A. H. A., and Hyde, K. D. 2011. The genus Phomopsis: Biology, applications, species concepts and names of common phytopathogens. Fungal Divers. 50:189-225.

Wang, F. 2012. Page 65 in: Identification, Distribution, Genetic Diversity and PCR Rapid Detection of Botryosphaeria spp. Causing Peach Tree Gummosis in China. Huazhong Agricultural University, China.

Wang, F., Zhao, L., Li, G., Huang, J., and Hsiang, T. 2011. Identification and characterization of Botryosphaeria spp. causing gummosis of peach trees in Hubei Province, central China. Plant Dis. 95:1378-1384.

Wang, L., Zhang, H., Zhao, Y., Chu, S., Wu, C., Tian, Y., and Hu, B. 2017. Development and Application of TaqMan Fluorescence Quantitative PCR for Detection of Phomopsis amygdali. Acta Phytopathol. Sin. 47:26-34.

Weaver, D. J. 1974. A gummosis disease of peach trees caused by Botryosphaeria dothidea. Phytopathology 64:1429-1432.

White, T. J., Bruns, T. D., Lee, S. B., and Taylor, J. W. 1990. Amplification and direct sequencing of fungal ribosomal RNA genes for phylogenetics. Pages 315-322 in: PCR Protocols - A Guide to Methods and Applications. M. A. Innis, D. H Gelfand, J. J. Sninsky, and T. J. White, eds. Academic Press, San Diego, CA.

Zhai, L., Zhang, M., Lv, G., Chen, X., Jia, N., Hong, N., and Wang, G. 2014. Biological and molecular characterization of four Botryosphaeria species isolated from pear plants showing stem wart and stem canker in China. Plant Dis. 98:716-726. 